\title{
Hallazgos Clínicos y Anatomopatológicos en Aves White Leghorn Ocasionados por Ornithobacterium rhinotracheale y Escherichia coli en Condiciones Controladas
}

\author{
Anatomopathological and Clinical Findings in White Leghorn Layers Caused by \\ Ornithobacterium rhinotracheale AND Escherichia coli UNDER CONTROLLED \\ Conditions
}

\author{
Manuel Colas C. ${ }^{1,5}$, Ivette Espinosa C. ${ }^{2}$, Nelson Merino G. ${ }^{3}$, Joiver Vichi L. ${ }^{2}$, José \\ López R. ${ }^{1}$, Manuel García C. ${ }^{1}$, Yanina Santana U. ${ }^{1}$, Alejandro Merino L. ${ }^{1}$, \\ Viviana Falcón C. ${ }^{4}$
}

\section{Resumen}

\begin{abstract}
El presente estudio tuvo como objetivo determinar los signos clínicos y los hallazgos anatomopatológicos ocasionados por Ornithobacterium rhinotracheale y Escherichia coli en aves de postura bajo condiciones controladas. Se seleccionaron 80 gallinas ponedoras White Leghorn de cinco semanas de edad. Previo al experimento, se realizaron análisis microbiológicos en 16 aves para chequear si habían sido expuestas a agentes microbianos. Las restantes 64 pollitas fueron distribuidas en cuatro grupos de 16 aves. G1 y G2 fueron inoculadas con 0.6 x 107 $\mathrm{UFC} / \mathrm{ml}$ de $O$. rhinotracheale en el día 1 del experimento, y G3 y G4 (control negativo) recibieron caldo cerebro corazón por vía intranasal. En las $48 \mathrm{~h}$ siguientes, G2 y G3 fueron inoculadas con 0.6 x $10^{7} \mathrm{UFC}$ de $E$. coli por vía intranasal. Cuatro pollitas por grupo fueron sacrificadas a los 3, 7, 14 y 21 días de la inoculación y se tomaron muestras de exudados de senos paranasales, tráquea, pulmón, sacos aéreos e hígado para microscopía óptica y electrónica de transmisión. Además se utilizaron técnicas histoquímicas (PAS y Weigert) para demostrar la presencia de mucus y fibrina en órganos respiratorios. El estudio permitió evidenciar un retardo del crecimiento y se demostró alteraciones del tejido linfoide asociado a mucosas en las pollitas inoculadas con $O$. rhinotracheale y E. coli.
\end{abstract}

Palabras clave: reproducción experimental, microscopía electrónica, $O$. rhinotracheale,

$$
\text { E. coli }
$$

${ }^{1}$ Área de Anatomía Patológica del Laboratorio de Investigación y Diagnóstico Aviar(LIDA), Instituto de Investigaciones Avícolas (IIA), Cuba

${ }^{2}$ Laboratorio de Microbiología Animal, Centro Nacional de Sanidad Agropecuaria (CENSA), Cuba

${ }^{3}$ Laboratorio de Control Biológico, Centro de Investigación de Desarrollo en Medicamento (CEDMED), Cuba

${ }^{4}$ Laboratorio de Microscopía Electrónica, Centro de Ingeniería Genética y Biotecnología (CIGB), Cuba

${ }^{5}$ E-mail: manuelcc@unah.edu.cu

Recibido: 7 de enero de 2014

Aceptado para publicación: 15 de junio de 2014 
This study aimed to determine the clinical signs and pathological findings caused for Ornithobacterium rhinotracheale and Escherichia coli in White Leghorn layers under controlled conditions. A total of 80 replacement hens of five weeks were selected. Before starting the experiment, microbiological tests were conducted in 16 chicks to verify if they were exposed to pathogens. The remaining 64 chicks were distributed in four equal groups $(\mathrm{n}=16)$. On day 1 of the experiment $\mathrm{G} 1$ and $\mathrm{G} 2$ were inoculated via intranasal with $0.6 \times 10^{7} \mathrm{UFC} / \mathrm{ml}$ of $O$. rhinotracheale and G3 and G4 (negative control) received brain heart infusion broth. Forty eight hours later, G2 and G3 were inoculated via intranasal with $0.6 \times 10^{7} \mathrm{UFC}$ of $E$. coli. Four chicks per group were slaughtered on days $3,7,14$, and 21 after inoculation and samples were collected from paranasal sinuses, trachea, lung, air sacs and liver for optic and transmission electron microscopy. In addition, histochemical techniques (PAS and Weigert) were used to show the presence of mucus and fibrin in respiratory organs. The study allowed evidencing a delay in the growth rate and presence of lymphoid tissue associated to mucosa in chicks inoculated with $O$. rhinotracheale and E. coli.

Key words: experimental reproduction, electron microscopy, O. rhinotracheale, E. coli

\section{INTRODUCCIÓN}

Entre las enfermedades infectocontagiosas de las aves, las respiratorias son las más importantes porque ocasionan grandes pérdidas económicas en la industria avícola y pueden tener múltiples causas (Bradbury y Morrow, 2008).

Entre los patógenos bacterianos de mayor importancia en la etiopatogenia de la Enfermedad Respiratoria Crónica (ERC) se destacan Avibacterium paragallinarum, Pasteurella multocida, Gallibacterium anatis biovar haemolytica, Staphylococcus spp y Escherichia coli, así como Mycoplasma gallisepticum y Mycoplasma synoviae (Christensen et al., 2003; Lobo et $a l .$, 2006; OIE, 2008). Desde la década del 90 se viene notificando la emergencia de serovares de Ornithobacterium rhinotracheale en infecciones respiratorias en pollos de ceba, pavos y gallinas ponedoras en menor cuantía, en países como EEUU, México, Argentina, Brasil, India, Perú e Irán, además de países africanos (Van Empel y Hafez,
1999; Van Veen et al., 2000a,b; Soriano et al., 2002; Turan y Ak, 2002; Canal et al., 2005; Murthy et al., 2008; Uriarte et al., 2010). En Cuba, entre los años 2009 y 2010, se determinó la presencia de anticuerpos a $O$. rhinotracheale mediante técnicas serológicas en gallinas ponedoras y sus reemplazos afectados por la ERC (Colas et al., 2010).

Existen reportes sobre las manifestaciones clínicas y lesiones del sistema respiratorio producidas por $O$. rhinotracheale en diferentes categorías y propósitos de crianza de aves (pollos de ceba y pavos, fundamentalmente). Estos signos son más severos cuando esta bacteria participa con otros agentes microbianos, como E. coli (Droual y Chin, 1996), Bordetella avium (Charlton, 1999), los adenovirus grupo I (Travers et al., 1996), y los virus de la enfermedad de Newcastle (ENC), bronquitis infecciosa (BI), anemia infecciosa y enfermedad infecciosa de la bolsa de Fabricio (EIB); estos dos últimos considerados como agentes inmunosupresores que afectan la respuesta inmune del hospedero (Thachil et al., 2009). 
En Cuba se desconocen las manifestaciones clínicas y los hallazgos anatomopatológicos de $O$. rhinotracheale como agente emergente y $E$. coli como enterobacteria oportunista en poblaciones de gallinas ponedoras y en sus reemplazos. Por esta razón, el presente estudio tuvo como objetivo determinar los signos clínicos y los hallazgos anatomopatológicos ocasionados por $O$. rhinotracheale y E. coli en condiciones controladas.

\section{Materiales y MéTOdos}

\section{Aislados Bacterianos}

Se utilizaron los aislados de $O$. rhinotracheale SI18 y E. coli obtenidos de gallinas ponedoras de la región occidental de Cuba. Estos fueron identificados por pruebas bioquímicas (api 20NE y 20 E Biomerieux, respectivamente) y conservados en glicerol a $-20{ }^{\circ} \mathrm{C}$.

Las bacterias se incubaron a $37{ }^{\circ} \mathrm{C}$, durante 48-72 horas, en placas de agar suplementada con $5 \%$ de sangre de carnero, en presencia de $\mathrm{CO}_{2}$ al $5 \%$ (Genbox, Oxoid) y caldo cerebro corazón (BHI, Oxoid) en condiciones de aerobiosis. La visualización de las características morfológicas de $O$. rhinotracheale se realizó por microscopía electrónica, para lo cual se tomó $0.5 \mathrm{ml}$ de la suspensión celular y se fijó en paraformaldehído al $4 \%$.

\section{Modelo Experimental}

Se trabajó con 80 pollitas de reemplazo de gallinas ponedoras White Leghorn, de cinco semanas de edad, que recibieron una alimentación estándar para su edad y propósito. Se inmunizaron con vacunas vivas contra viruela aviar, BI, enfermedad de Marek (al día de edad), EIB y ENC (10 y 14 días, respectivamente), según el programa de vacunación vigente en Cuba. Las aves se ubicaron en jaulas dentro de una nave de experimentación con barreras físicas de contención y medidas de bioseguridad para preservar el bienestar de las aves y minimizar fugas al ambiente de los agentes bacterianos utilizados en el experimento.

Se hizo un muestreo serológico a 16 aves empleando las técnicas de Seroaglutinación rápida en placa (M. gallisepticum), ELISA (O. rhinotracheale) e Inhibición de la hemoaglutinación (HI) contra Newcastle e Influenza Aviar (IA) serotipos H5 y H7. Además, se tomaron exudados de tráquea individual y mezcla de cuatro aves con la finalidad de determinar si las aves habían sido expuestas anteriormente a estos agentes bacterianos, incluyendo además a $E$. coli (Espinosa et al., 2011) y virales (OIE, 2008).

El primer (A) y segundo (B) grupo fueron inoculados por vía intranasal con $0.2 \mathrm{ml}$ de cultivo puro de aislado de $O$. rhinotracheale SI18 (0.6 X 10 $\left.10^{7} \mathrm{UFC} / \mathrm{ml}\right)$, en tanto que el tercer grupo $(\mathrm{C})$ recibió solo $0.2 \mathrm{ml}$ de BHI. A las $48 \mathrm{~h}$ siguientes, B y C recibieron $0.2 \mathrm{ml}$ de cultivo puro de $E$. coli $\left(0.6 \times 10^{7} \mathrm{UFC} / \mathrm{ml}\right)$, y el cuarto grupo (D) recibió solo $0.2 \mathrm{~mL}$ de $\mathrm{BHI}$. Las dosis de inoculación utilizadas para $O$. rhinotracheale y E. coli se seleccionaron según lo notificado por Zaini et al. (2008) y Yaguchi et al. (2009), respectivamente.

\section{Análisis Bacteriológico}

El examen clínico a las aves de todos los grupos se realizó a los 3, 7, 14 y 21 días pos-inoculación (PI). Se seleccionaron y pesaron cuatro pollitas al azar de cada grupo experimental con el uso de una balanza KERN PFB (1200 g). Finalmente, se sacrificaron por la metodología de necropsia descrita por Sánchez y Lamazares (2010).

Se tomaron muestras de exudados de senos paranasales, fragmentos de tráquea, pulmón y sacos aéreos. Las muestras se sembraron en placas de agar base Columbia, suplementada con $5 \%$ de sangre de carnero en presencia de $\mathrm{CO}_{2}$ al 5\% (Genbox, Oxoid) y BHI (Oxoid) en condiciones de aerobiosis. A 
Cuadro 1. Secuencias nucleotídicas de los oligonucleótidos y las reacciones de PCR utilizadas en la amplificación del ADN de $O$. rhinotracheale en un Termociclador de ADN (Mastercycler ${ }^{\circledR}$ personal, Eppendorf AG)

\begin{tabular}{|c|c|c|c|c|c|}
\hline \multirow{2}{*}{$\begin{array}{l}\text { Talla } \\
(\mathrm{Pb})\end{array}$} & \multirow{2}{*}{$\begin{array}{l}\text { Secuencia de oligonucleótidos } \\
\qquad\left(5^{\prime}-3^{\prime}\right)\end{array}$} & \multicolumn{3}{|c|}{ Condiciones PCR $\left({ }^{\circ} \mathrm{C} / \mathrm{seg}\right)$} & \multirow{2}{*}{ Referencia } \\
\hline & & Des. ${ }^{1}$ & Hib. ${ }^{1}$ & Ext. $^{1}$ & \\
\hline 784 & $\begin{array}{l}\text { GAGAATTAATTTACGGATTAAG } \\
\text { TTCGCTTGGTCTCCGAAGAT }\end{array}$ & $98 / 120$ & $65 / 90$ & $72 / 60$ & $\begin{array}{l}\text { Van Empel, } \\
1998\end{array}$ \\
\hline
\end{tabular}

${ }^{1}$ Des.: Desnaturalización; Hib.: Hibridización; Ext.: Extensión

Cuadro 2. Escala para evaluar el daño de los órganos (senos paranasales, tráquea y pulmones) del sistema respiratorio en aves

\begin{tabular}{llc}
\hline & Descripción & Puntos \\
\hline Tipo de exudado inflamatorio & Sin alteraciones aparentes (SAA) & 0 \\
& Exudado catarral moderado & 1 \\
& Exudado catarral abundante & 2 \\
& Exudado mucofibrinoso & 3 \\
Daño epitelial y glandular & Pérdida focal de cilios & 1 \\
& Hiperplasia epitelial & 2 \\
& Metaplasia del epitelio & 3 \\
& Atrofia glandular & 4 \\
\hline
\end{tabular}

las 24 h de incubación, las colonias sospechosas a $O$. rhinotracheale fueron cultivadas e identificadas por pruebas bioquímicas.

\section{Identificación Molecular de $O$. rhino- tracheale}

La confirmación molecular de $O$. rhinotracheale se realizó mediante PCR con cebadores específicos para este microorganismo (Cuadro 1). Los productos amplificados fueron visualizados con bromuro de etidio $(0.5 \mu \mathrm{g} / \mathrm{ml})$ en electroforesis de ADN en gel de agarosa al $0.8 \%$, a 70 v por $1 \mathrm{~h}$ (Espinosa et al., 2011).

\section{Estudio Anatomopatológico}

Se realizó una descripción de las lesiones macroscópicas y se tomaron muestras de fragmentos de senos paranasales, tráquea, pulmones, sacos aéreos e hígado. Las muestras se fijaron en formol neutro al $4 \%$, se procesaron y colorearon con HematoxilinaEosina (HE). Se emplearon las técnicas histoquímicas no enzimáticas de PAS (ácido periódico-Schiff) y de hematoxilina férrica de Weigert para demostrar la presencia de mucus y fibrina, respectivamente, en órganos respiratorios. 
Se procesaron por microscopía electrónica muestras de tejido pulmonar de cuatro aves del grupo A correspondientes a los 3 y 7 días posinfección (PI). Fragmentos de $1 \mathrm{~mm}$ de pulmones fueron fijados en glutaraldehído al $3.2 \%$. Estas muestras y la suspensión celular fijada en paraformaldehído al $4 \%$ se deshidrataron con concentraciones crecientes de etanol y se incluyeron en resina Spurr. Posteriormente, se contrastaron con acetato de uranilo saturado y citrato de plomo y se examinaron con un microscopio electrónico JEOL JEM-2000EX. Las microfotografías se analizaron a un micrómetro de magnificación.

En la interpretación histopatológica del grado de intensidad del exudado inflamatorio y del daño epitelial y glandular en senos paranasales, tráquea y pulmón se siguieron los criterios descritos en el Cuadro 2. Se sumaron los grados de intensidad de las lesiones en cada ave según la escala siguiente: $0=$ SAA (0), 1-3 = moderado (I); >4 = severo (II).

Las lesiones microscópicas crónicas de los sacos aéreos se clasificaron según la escala semicuantitativa de grado de intensidad en el estudio del mesotelio y submucosa: $0=$ SAA (0); I = moderada (escasa proliferación del tejido conectivo); II = severa (abundante tejido conectivo).

Para la determinación de la respuesta inmune inespecífica (hiperplasia) del tejido linfoide asociado a mucosas de los senos paranasales (NALT) y bronquios (BALT), se aplicó la siguiente escala propuesta en este trabajo: $0=\mathrm{SAA} ; \mathrm{I}=$ hiperplasia moderada; II = hiperplasia severa.

\section{Análisis Estadístico}

Se realizaron comparaciones de proporciones para cada lesión macroscópica de diferentes grados de intensidad histopatológica de la hiperplasia del NALT y BALT en cada órgano respiratorio (senos paranasales, tráquea y pulmones) entre cada grupo experimental. Se utilizó la Dócima de Duncan para evidenciar las diferencias entre grupos expe- rimentales con niveles de confianza al $95 \%$. Se utilizó el programa COMPAPRO v. 2.1 (Ecosoft, Inc).

Se realizó la comparación de los valores de peso vivo entre el grupo control y los grupos inoculados con los dos agentes bacterianos e independientes en los distintos días PI. Se analizó la normalidad de los datos mediante el método de Kolmogorov-Smirnov (K-S) y se verificó si cumplía con la homogeneidad de varianza por la prueba de Levene. Posteriormente, como los datos no seguían una distribución normal, se realizó la prueba no paramétrica Kruskal-Wallis, apoyado con el paquete estadístico Minitab 14.

\section{Resultados}

No se evidenció la presencia de $O$. rhinotracheale, M. gallisepticum, E. coli, ni los virus de BI, ENC e IA en el monitoreo microbiológico preliminar realizado a las 16 aves. Las pruebas serológicas para la detección de anticuerpos a $M$. gallisepticum y $O$. rhinotracheale fueron negativas para los sueros de las 80 aves. Asimismo, las pollitas mantenidas como control no manifestaron signos clínicos ni lesiones durante el experimento.

No se apreciaron signos clínicos respiratorios en ningún grupo experimental; sin embargo, se apreció una tendencia a la disminución de los pesos vivos (Cuadro 3) en los tres grupos inoculados con los agentes bacterianos con respecto a las del grupo control.

En el Cuadro 4 se aprecian que las lesiones macroscópicas son más evidentes en el grupo B con respecto a los otros dos grupos inoculados con bacterias independientes $(\mathrm{p}<0.05)$. Asimismo, la degeneración hepática se observó con mayor proporción en el grupo $\mathrm{B}$ y $\mathrm{C}$ con respecto al grupo A $(\mathrm{p}<0.05)$. Por otro lado, no se observaron alteraciones macroscópicas aparentes en las articulaciones.

En la Fig. 1 se evidencia que desde el día 7 al 21 PI se observa una tendencia al 
Cuadro 3. Peso vivo (promedio \pm error estándar, en gramos) de aves inocu ladas con aislados de Ornithobacterium rhinotracheale (A), O. rhinotracheale y E. coli (B), E. coli (C) y grupo control sin inóculo (D)

\begin{tabular}{ccccc}
\hline \multirow{2}{*}{$\begin{array}{c}\text { Días pos- } \\
\text { inoculación }\end{array}$} & A & B & C & D \\
\cline { 2 - 5 } & Media \pm EE & Media \pm EE & Media \pm EE & Media \pm EE \\
\hline 3 & $547 \pm 6$ & $547 \pm 6$ & $547 \pm 6$ & $552 \pm 4$ \\
7 & $591 \pm 5$ & $572 \pm 9$ & $578 \pm 9$ & $630 \pm 4$ \\
14 & $683 \pm 11$ & $663 \pm 13$ & $673 \pm 11$ & $720 \pm 8$ \\
21 & $708 \pm 16$ & $685 \pm 6$ & $691 \pm 6$ & $788 \pm 4$ \\
\hline
\end{tabular}

Cuadro 4. Frecuencia (\%) de lesiones macroscópicas en pollitas de reemplazos ${ }^{1}$ inoculadas con aislados de Ornithobacterium rhinotracheale (A), O. rhinotracheale y E. coli (B), E. coli (C)

\begin{tabular}{|c|c|c|c|c|}
\hline \multicolumn{2}{|c|}{ Lesiones macroscópicas } & A & B & $\mathrm{C}$ \\
\hline \multicolumn{2}{|c|}{ Rinitis catarral } & $38^{\mathrm{a}}$ & $38^{\mathrm{a}}$ & $25^{\mathrm{a}}$ \\
\hline \multicolumn{2}{|c|}{ Rinitis mucofibrinosa } & $0^{\mathrm{b}}$ & $25^{\mathrm{a}}$ & $0^{\mathrm{b}}$ \\
\hline \multicolumn{2}{|c|}{ Exud ado catarral en tráquea ${ }^{2}$} & $44^{\mathrm{a}}$ & $44^{\mathrm{a}}$ & $0^{\mathrm{b}}$ \\
\hline \multirow{2}{*}{$\begin{array}{l}\text { Focos } \\
\text { neumónicos }\end{array}$} & Unilateral & $0^{\mathrm{b}}$ & $25^{\mathrm{a}}$ & $0^{\mathrm{b}}$ \\
\hline & Bilateral & $6^{\mathrm{a}}$ & $6^{\mathrm{a}}$ & $0^{\mathrm{a}}$ \\
\hline \multicolumn{2}{|c|}{ Degeneración hepática } & $6^{\mathrm{b}}$ & $50^{\mathrm{a}}$ & $44^{\mathrm{a}}$ \\
\hline
\end{tabular}

${ }^{1} 16$ aves por grupo

${ }^{a, b}$ Superíndices diferentes dentro de filas indican diferencias significativas $(p \varangle 0.05)(2: p \varangle 0.01)$

incremento de la intensidad de las lesiones microscópicas en los órganos del sistema respiratorio de los grupos inoculados con $O$. rhinotracheale.

En la Fig. 2 se muestra la proporción de las lesiones microscópicas en los senos paranasales, con grados de intensidad moderado y severo, en todos los grupos experimentales. Se observaron cambios histopatológicos como hiperestimulación del sistema mucociliar, presencia de mucus con exudado de naturaleza fibrinosa, hiperplasia del NALT con mayor predominio en el epitelio respiratorio con respecto al tejido olfatorio, y rinitis crónica caracterizada por hiperplasia epitelial con infiltración de células mononucleares.

Las lesiones de grado moderado en tráquea se presentaron en los tres grupos experimentales mientras el grado severo solo se apreció en las pollitas del Grupo B (Fig. 3). En la evaluación histopatológica se observó hipersecreción de mucus en todos los grupos y fibrina especialmente en el Grupo C. Por otro lado, no se observaron diferencias es- 
tadísticas entre grupos ni entre grados de intensidad de lesiones histopatológicas (Fig. 4).

Las principales lesiones microscópicas observadas en los bronquios en el grupo B fueron la hiperplasia del BALT y la hipersecreción de mucus mezclada con fibrina, que provocaron estenosis bronquial y de los túbulos pulmonares.

O. rhinotracheale se aisló por cultivo e identificó por PCR a los 3 y 7 días PI a partir de los senos paranasales; sin embargo, se pudo observar por microscopía electrónica la colonización de una bacteria compatible con $O$. rhinotracheale en el intersticio (Fig. 5C) y en el interior de un macrófago (Fig. 5D) del tejido pulmonar y se pudo demostrar el pleomorfismo típico de $O$. rhinotracheale en la suspensión celular (Fig. $5 \mathrm{~A})$.

En total, 6, 19 y 19 pollitas presentaron aerosaculitis crónica en los grupos A, B y C, respectivamente, pero sin diferencia estadística entre grupos. La aerosaculitis se caracterizó desde el punto de vista histopatológico por una fuerte respuesta inflamatoria del mesotelio con infiltración de células mononucleares, macrófagos y proliferación de tejido conectivo.

La frecuencia de aves afectadas, según tratamiento, con hiperplasia de tejido linfoide en senos paranasales y pulmones se muestra en la Fig. 6. Se observa una mayor frecuencia en las aves del grupo B, donde la intensidad de la hiperplasia del NALT fue moderada y severa en los tres grupos, en tanto que la hiperplasia del BALT en pulmones solo mostró estos grados en las aves del grupo B. Microfotografías representativas de hiperplasia del NALT y BALT se muestran en las Figs. 7 y 8, respectivamente.

Esteatosis hepática se observó en el 19, 81 y $31 \%$ de las aves de los grupos A, B y C (16 aves por grupo). El daño se caracterizó principalmente por la formación de micro y macrovesículas alrededor de la zona 3 del acinus hepático.

\section{Discusión}

La expresión de los signos clínicos debido a una infección microbiana depende de la interacción microorganismo-hospedero. En este aspecto intervienen la virulencia del microorganismo, que se caracteriza por la capacidad de adherencia, colonización, invasión de los tejidos y subversión de las funciones celulares del hospedero (Taylor et al., 2009). Por otra parte, existen características propias del hospedero como la edad y el estado inmune (Montassier, 2009). En condiciones experimentales controladas también son importantes las vías de inoculación y la dosis utilizada (Kilic et al., 2010).

La ausencia de signos clínicos respiratorios en las pollitas del estudio pudo deberse a causas como la hiperestimulación del NALT y BALT, especialmente en el grupo B, y al control de los factores predisponentes (temperatura, humedad, alimentación y manejo de las aves), dosis y vía de inoculación utilizadas, así como a la virulencia de los aislados utilizados.

Droual y Chin (1996) y Van Empel (1998) refieren que existen discrepancias en la patogenicidad de $O$. rhinotracheale, debido a que, en sus condiciones, no lograron reproducir los signos clínicos y las lesiones que se observaron en infecciones naturales. Asimismo, Travers et al. (1996) y Sprenger et al. (2000) notifican diferencias en las manifestaciones clínicas y en los hallazgos anatomopatológicos entre los aislamientos estudiados. Sin embargo, en este estudio se encontró una tendencia al retardo en el crecimiento de las pollitas de los tres grupos inoculados. Retardo en el crecimiento e inapetencia han sido, no obstante, reportadas en inoculaciones experimentales con $O$. rhinotracheale (Van Empel et al., 1996). También se debe destacar una posible anemia ante la palidez marcada de la cresta y barbillas, el retardo del crecimiento y lesiones en senos paranasales, tráquea, bronquios y túbulos pulmonares. 


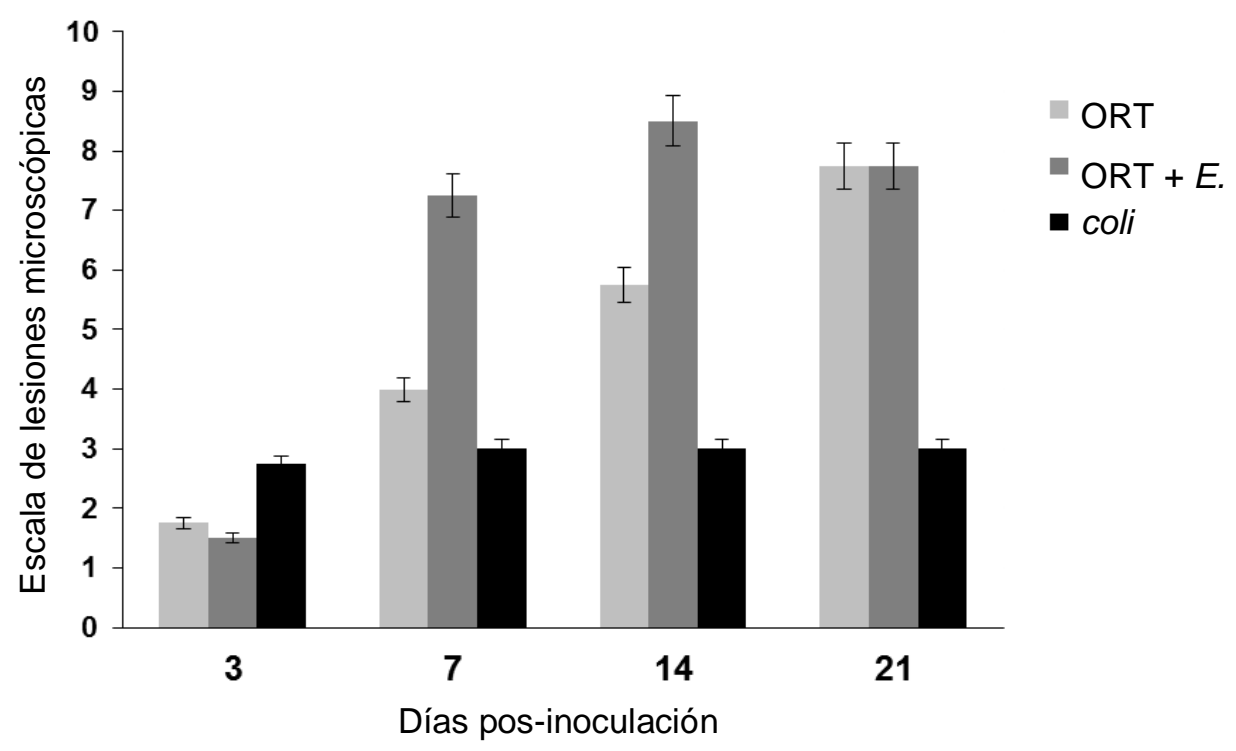

Figura 1. Intensidad de lesiones microscópicas en órganos del sistema respiratorio de pollitas de postura de cinco semanas inoculadas con aislados de Ornithobacterium rhinotracheale (ORT), O. rhinotracheale y E. coli, y E. coli. Cuatro aves por grupo en cada tiempo de evaluación. Se muestra la suma de los grados de lesiones (1-3: grado moderado, mayores de 4: grado severo)
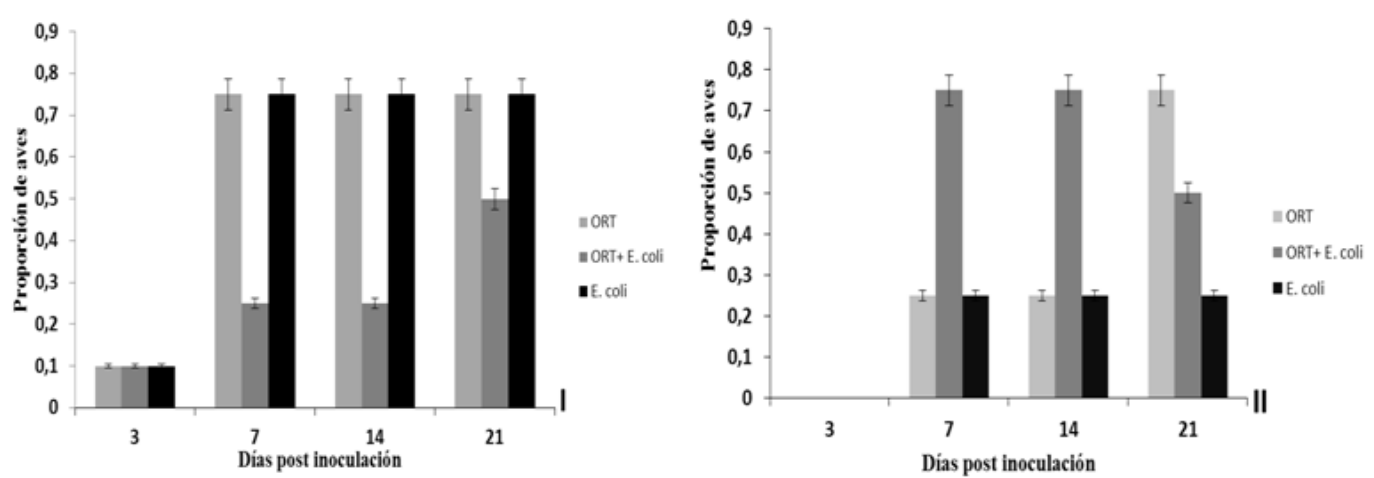

Figura 2. Proporción de aves con lesiones histológicas en los senos paranasales según el grado de intensidad en los grupos experimentales. I. Moderado; II. Severo. No hubo diferencia estadística entre tratamientos 

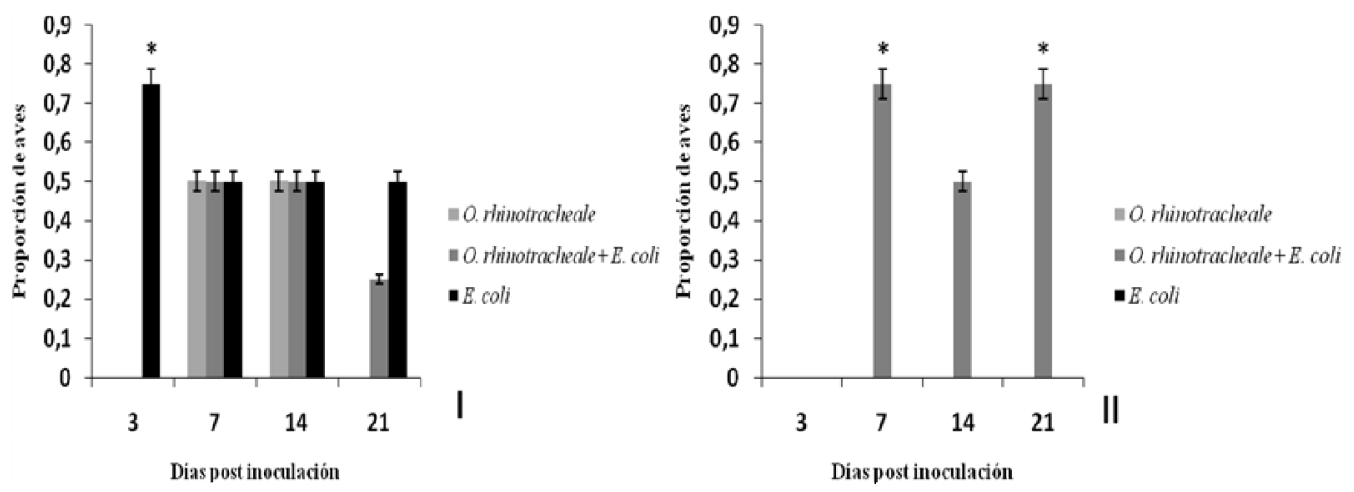

Figura 3. Proporción de aves con lesiones histológicas en las tráqueas según el grado de intensidad en los grupos experimentales. I. Moderado. II. Severo. El asterisco $\left(^{*}\right)$ indica diferencia estadística entre grupos experimentales en cada grado de intensidad $(\mathrm{p}<0.05)$
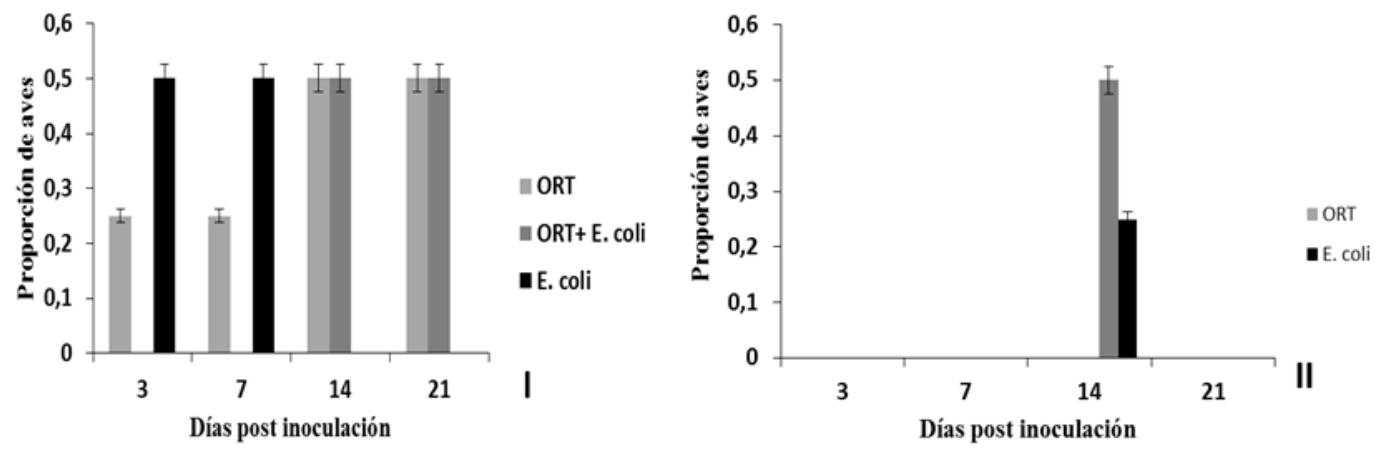

Figura 4. Proporción de aves con lesiones histológicas en pulmones según el grado de intensidad en los grupos experimentales. I. Moderado. II. Severo. No hubo diferencia estadística entre tratamientos

Los hallazgos macroscópicos fueron similares a aquellos del estudio de Thachil et al. (2009) en una reproducción experimental con gallinas ponedoras inoculadas por vía aerógena con aislados de $O$. rhinotracheale y E. coli. Sin embargo, estos autores refieren un grupo experimental con infección por $O$. rhinotracheale, E. coli y el virus de la $\mathrm{BI}$, donde encontraron lesiones más relevantes como traqueítis, neumonía, aerosaculitis y peritonitis.
La no evidencia de alteraciones macroscópicas aparentes en las articulaciones difiere de los resultados de Soriano et al. (2000), quienes observaron lesiones macroscópicas en senos infraorbitarios, tráquea, pulmones, sacos aéreos y articulaciones en pollos de ceba inoculados con $O$. rhinotracheale.

La tendencia en el incremento de las lesiones microscópicas en los senos paranasales que se apreciaron en los grados 


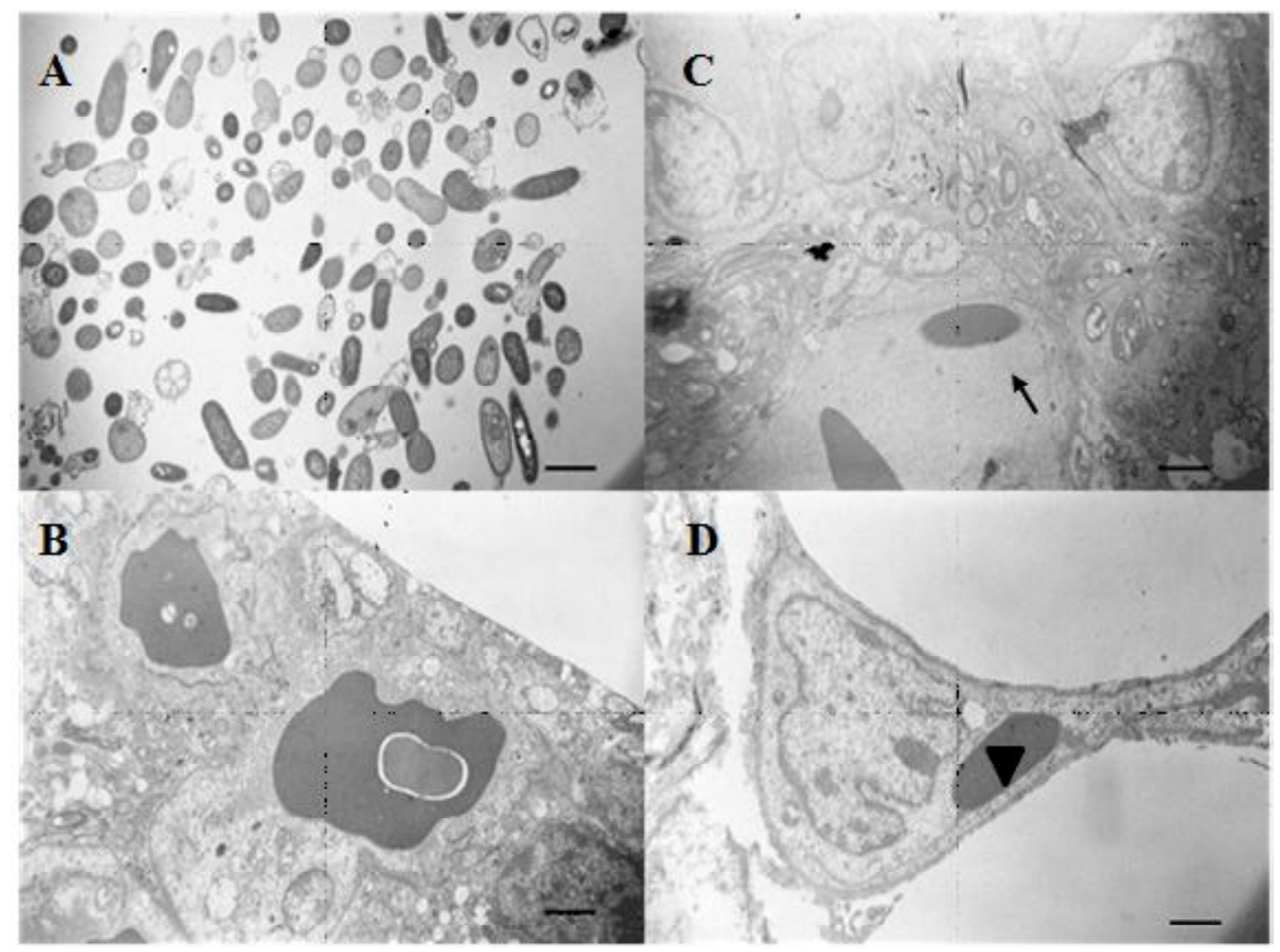

Figura 5. A. Grupo control, cultivo de $O$. rhinotracheale $\left(6 \times 10^{6} \mathrm{UFC} / \mathrm{ml}\right)$. Se observa pleomorfismo de la bacteria. B. Grupo D, tejido pulmonar sin alteración aparente. C: Grupo A, colonización de $O$. rhinotracheale en el intersticio pulmonar (flecha) a los 7 días de la inoculación. D: Grupo D, O. rhinotracheale fagocitado por el macrófago (cabeza de flecha) a los 7 días de la inoculación. Microscopía electrónica de transmisión, $2000 \mathrm{EX}$
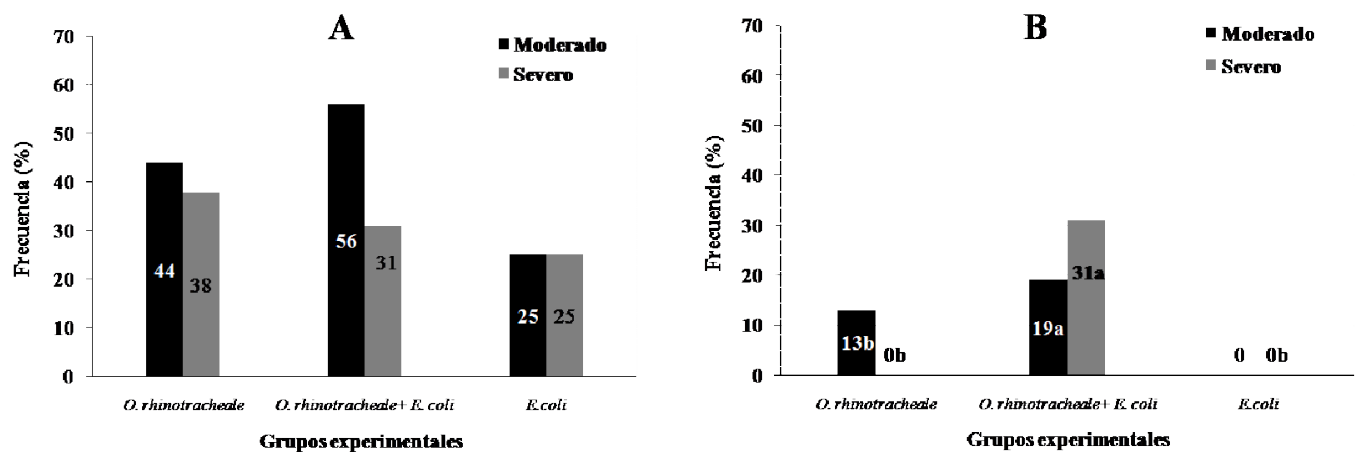

Figura 6. Frecuencia de aves positivas con diferentes grados de focalización de la hiperplasia del tejido linfoide asociado a mucosa en senos paranasales (NALT). (A). En pulmones (BALT) (B) 


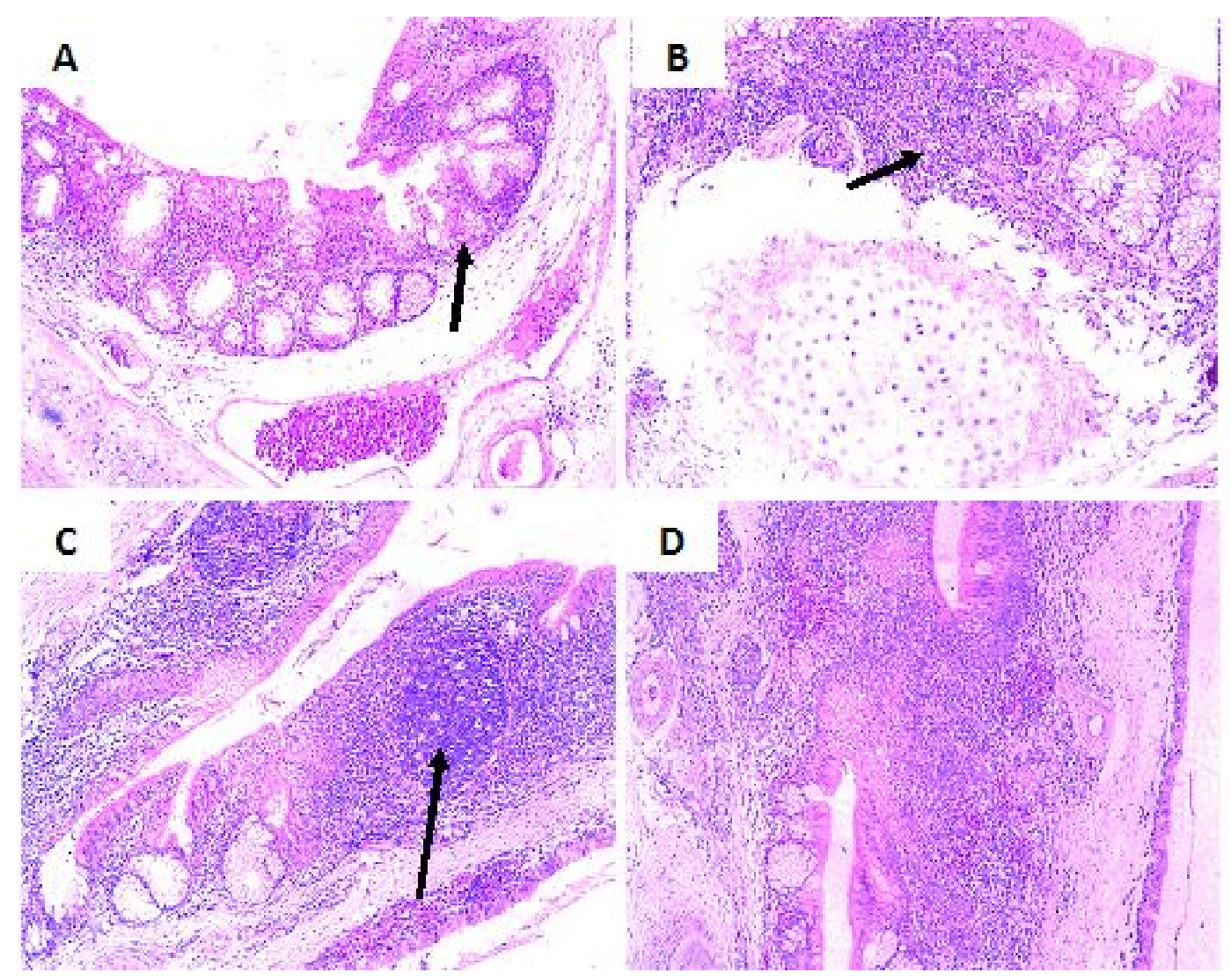

Figura 7. Microfotografías de seno paranasal de pollitas inoculadas con $O$. rhinotracheale y E. coli, donde se observan diferentes grados de hiperplasia del NALT a los 14 días de la inoculación. (A y B). Intensidad moderada (flechas). (D y E). Intensidad severa que se caracteriza por la formación de centros germinativos (flecha). HE. 400X

de intensidad moderado y severo, está dada por la colonización primaria a través de la vía intranasal utilizada. Se pudo observar hiperplasia del NALT en grado severo con más predominio en la región respiratoria con respecto a la olfatoria, en la cual se formaron folículos linfoides organizados (Fig. 7). Ohshima e Hiramatsu (2000) señalan que este tejido linfoide se encuentra presente principalmente en el epitelio respiratorio y relativamente poco frecuente en la región olfatoria y se estimula ante la participación de agentes microbianos.
El comportamiento de la hiperplasia del NALT depende de la adherencia, colonización y diseminación de las entidades bacterianas en este órgano. Maina y Cowley (1998) y Maina (2002) destacan que las partículas que son transportadas más allá de la mucosa ciliar pueden ser eliminadas por mecanismos celulares y por los agregados linfoides asociados a mucosas presentes en el epitelio respiratorio.

Las alteraciones microscópicas observadas en los bronquios, como la hiperplasia del BALT y la hipersecreción de mucus mez- 


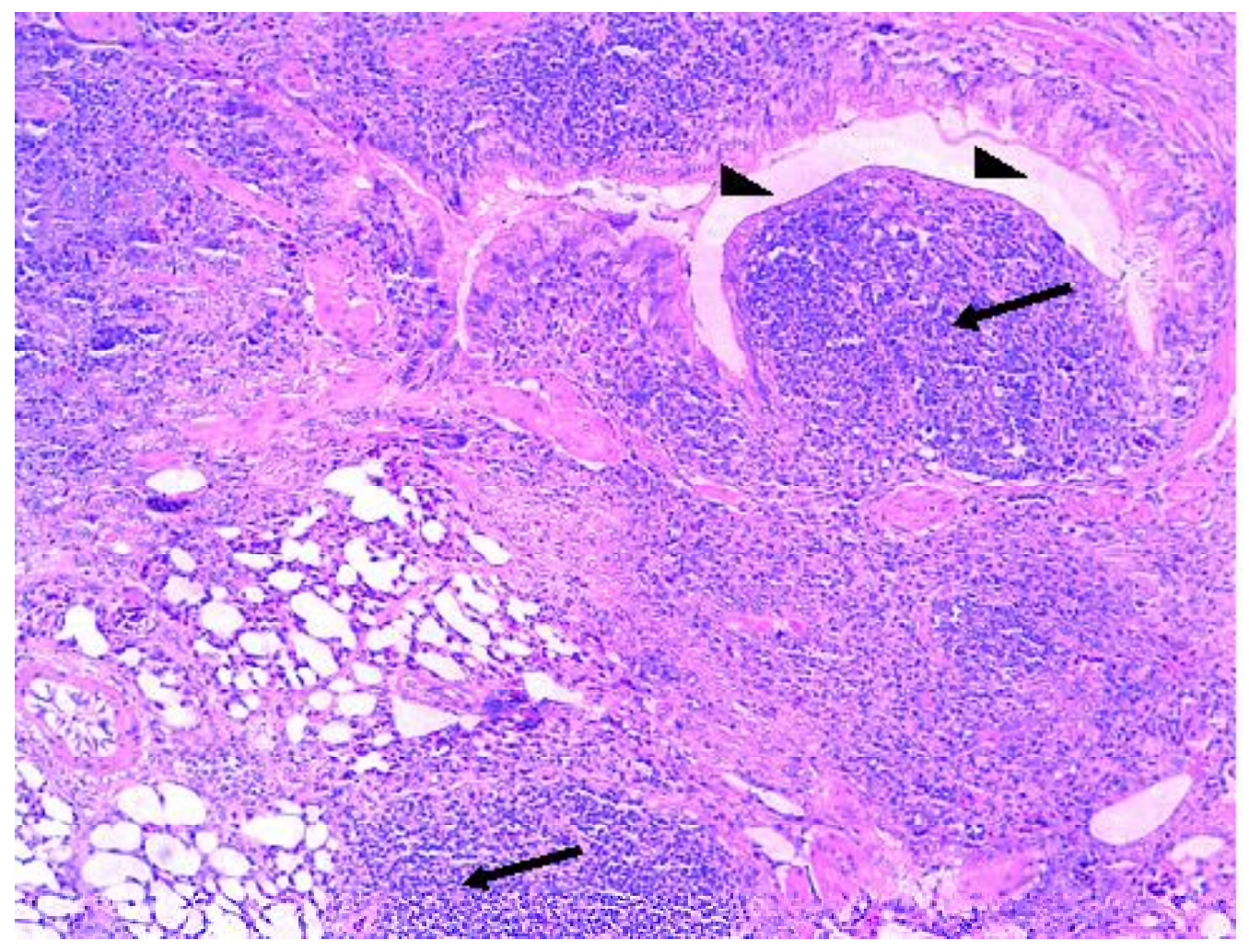

Figura 8. Microfotografía de bronquio de pollitas inoculadas con $O$. rhinotracheale y E. coli. Se aprecia estenosis bronquial y de túbulos pulmonar e hiperplasia del tejido linfoide asociado a mucosa (BALT, flecha), con hipersecreción de mucus en la luz bronquial (cabeza de flecha). HE, 400X

clada con fibrina, provocaron la estenosis bronquial y de los túbulos pulmonares. Esta hiperplasia del BALT que se observa en los pulmones sugiere que $O$. rhinotracheale y la interacción con $E$. coli son responsables de las alteraciones del tejido linfoide asociado a mucosas (BALT) y del sistema mucociliar.

La aerosaculitis se pudo deber a las características de los pulmones y los sacos aéreos (zonas de intercambio de oxígeno), altamente susceptibles a la colonización e invasión bacteriana, debido a la escasa existencia de macrófagos alveolares para contener la infección a estos niveles. Por otra parte, la barrera existente entre la red capilar aérea y la sangre es extremadamente fina (Mellata et al., 2003).
El hígado juega un papel predominante en la resolución de la infección bacteriana, por lo que la presencia de la esteatosis se puede deber a la infección sistémica por $E$. coli que fuera inoculada en las pollitas. La $E$. coli que ingresa a través de la inhalación, se disemina por el torrente circulatorio y se produce la colonización en otros órganos del hospedero (hígado, bazo y corazón), debido a la capacidad de adhesión mediada por las fimbrias $\mathrm{P}$ en fases avanzadas de la infección (Monroy et al., 2005).

Los resultados obtenidos demuestran que $O$. rhinotracheale y $E$. coli inoculados en las pollitas incrementan las alteraciones histopatológicas del tejido linfoide asociado a mucosas, tales como hiperplasia del NALT y BALT. Además, se encontraron otras alte- 
raciones en el sistema respiratorio, como rinitis, traqueítis y aerosaculitis caracterizada por una hiperplasia epitelial con infiltración de linfocitos.

\section{Conclusiones}

En las pollitas de reemplazo de gallinas ponedoras inoculadas con $O$. rhinotracheale y E. coli se evidencia un retardo del crecimiento y se encontraron alteraciones del tejido linfoide asociado a mucosas de senos paranasales y bronquios.

\section{Literatura Citada}

1. Bradbury J, Morrow M. 2008. Avian mycoplasmas. En: Pattison M, McMullin PF, Bradbury JM, Alexander DJ (eds). Poultry diseases. $12^{\text {th }}$ ed. USA: Elsevier. p 220-227.

2. Canal CW, Leao JA, Rocha SLS, Macagnan M, Lima Rosa CAV, Oliveira SD, Back A. 2005. Isolation and characterization of Ornithobacterium rhinotracheale from chickens in Brazil. Res Vet Sci 78: 225-230. doi: 10.1016/j.rvsc.2004.10.003

3. Charlton BR. 1999. Bordetella avium and Ornithobacterium rhinotracheale from California poultry submissions. In: Proc $48^{\text {th }}$ Western Poultry Disease Conference. Canada: American Association of Pathologists. p 80.

4. Christensen H, Bisgaard M, Bojesen M, Mutters R, Olsen E. 2003. Genetic relationships among avian isolates classified as Pasteurella haemolytica, Actinobacillus salpingitidis or Pasteurella anatis with proposal of Gallibacterium anatis gen. nov., comb. nov. and description of additional genomospecies within Gallibacterium gen. nov. Int J Syst Evol Microbiol 53: 275-287. doi: 10.1099/ijs.0.02330-0
5. Colas M, Merino A, Santana Y, Miranda Y, Bacallao N, Lobo E, Vega A. 2010. Estudio serológico de agentes asociados con el síndrome respiratorio crónico en gallinas ponedoras. Rev Biotecnol Aplicada 27: 227-331.

6. Droual R, Chin RP. 1996. Interaction of Ornithobacterium rhinotracheale and Escherichia coli O78, H9 when inoculated into the air sac in turkey pounts. In: Proc $45^{\text {th }}$ Western Poultry Dissease Conference. Quintana Roo, México: American Association of Avian Pathologist. p 11.

7. Espinosa I, Colas M, Vichi J, Báez M, Martínez S. 2011. Aislamiento e identificación de Ornithobacterium rhinotracheale en gallinas ponedoras de granjas de la provincia La Habana. Rev Salud Anim 33: 38-43.

8. Kilic A, Timurkaan N, Erta HB, Yilmaz F. 2009. Pathological examination and bacterial reisolation by culture and PCR of experimental Ornithobacterium rhinotracheale infection in broiler chickens. Revue Méd Vét 160: 140-144.

9. Lobo E, Martínez S, Agüero JA, Chávez Y, Rosado I. 2006. Síndrome respiratorio crónico de las aves. Etiología, diagnóstico y control. Rev Cub Cienc Avícola 30: 27-40.

10. Maina JN, Cowley HM. 1998. Ultraestructural characterization of the pulmonary cellular defences in the lung of bird the rock dove Columba livia. Proc Biol Sci 265: 1567-1572.

11. Maina JN. 2002. Some recent advances on the study and understanding of the functional design of the avian lung: morphological and morphometric perspectives. Biol Rev Camb Philos Soc 77:97-152. doi:10.1017/S1464793101005838

12. Mellata M, Dho-Moulin M, Dozois CM, Curtiss R, Lehoux B, Fairbrother JM. 2003. Role of avian pathogenic Escherichia coli virulence factors in 
bacterial interaction with chicken heterophils and macrophages. Infect Immun 71: 494-503.

13. Monroy MA, Knöbl T, Bottino JA, Ferreira CS, Ferreira AJ. 2005. Virulence characteristics of Escherichia coli isolates obtained from broiler breeders with salpingitis comparative. Comp Immunol Microbiol Infect Dis 28: 1-15. doi: 10.1016/j.cimid.2004.03.001

14. Montassier HJ. 2009. Doenças por sistema (Seçao 3). En: Berchieri A, Nepomuceno E, et al. (eds). Doenças das aves. $2^{\mathrm{a}}$ ed. Campinas, SP, Brazil: FACTA - Fundaçao APINCO de Ciencia e Tecnologias Avícolas. p 391-415.

15. Murthy GK, Natarajan D, Gurusamypalayam AB, Arunachalapillai M. 2008. Pathogenic bacteria related to respiratory diseases in poultry with reference to Ornithobacterium rhinotracheale isolated in India. Vet Arhiv 78: 131-140.

16. Ohshima K, Hiramatsu K. 2000. Distribution of T-cell subsets and immunoglobulin-containing cells in nasalassociated lymphoid tissue (NALT) of chickens. Histol Histopathol 15: 713-720.

17. [OIE] World Organisation for Animal Health. 2008. OIE listed diseases and other diseases of importance to international trade. In: Manual of diagnostic test and vaccines for terrestrial animals (mammals, birds and bees). $6^{\text {th }}$ ed. Vol 1-2. Paris: OIE, Biological Standard Commmission.

18. Sánchez A, Lamazares MC. 2010. Principales enfermedades que afectan a las aves. Micoplasmosis aviar. En: Sánchez A, et al. (eds) Salud y producción de las aves. La Habana, Cuba: Ed Felix Varela. p 212-532.

19. Soriano VE, Fernández RP, Téllez GI. 2000. Ornithobacterium rhinotracheale: un agente patógeno emergente en avicultura. Vet Méx 31: 245-253.

20. Soriano VE, Longinos $A M G$ Navarete BPG Fernández RP. 2002. Identification and characterization of Ornithobacterium rhinotracheale isolates from Mexico. Avian Dis 46: 686-690.
21. Sprenger SJ, Halvorson DA, Nagaraja KV, Spasojevic R, Dutton RS, Shaw DP. 2000. Ornithobacterium rhinotracheale infection in commercial laying type chickens. Avian Dis 44: 725-729.

22. Taylor P, Day T, Nagy D, Wild G, Andre JB, Gardner A. 2006. The evolutionary consequences of plasticity in host-pathogen interactions. Theor Popul Biol 69: 323-331. doi: 10.1016/ j.tpb.2005.09.004

23. Thachil J, Velayudhan VT, Shaw DP, Halvorson DA, Nagaraja KV. 2009. Pathogenesis of Ornithobacterium rhinotracheale in egg-laying hens with coexisting infectious bronchitis virus and Escherichia coli infections. J Appl Poultry Res 18: 780-788. doi: 10.3382/ japr.2009-00039

24. Travers AF, Coetzee L, Gummow B. 1996. Pathogenicity differences between South African isolates of Ornithobacterium rhinotracheale. J Vet Res 63: 197-207.

25. Turan N, Ak S. 2002. Investigation of the presence of Ornithobacterium rhinotracheale in chickens in turkey and determination of the seroprevalence of the infection using the enzyme-linked immunosorbent assay. Avian Dis 46: 442446.

26. Uriarte J, Suzuki K, Origlia J, Gornatti D, Píscopo M, Cerda R, Herrero $M$, et al. 2010. Stochastic estimation of seroprevalence against Ornithobacterium rhinotracheale and avian Pneumovirus among chickens in Argentina. Int J Poultry Sci 9: 352-356.

27. Van Empel PCM. 1998. Ornithobacterium rhinotracheale: current status and control. In: Proc 1st International Symposium on Turkey Diseases. Berlin.

28. Van Empel P, Van Den Bosch $H$, Goovaerts D, Storm P. 1996. Experimental infection in turkeys and chickens with Ornithobacterium rhinotracheale. Avian Dis 40: 858-864.

29. Van Empel PCM, Hafez HM. 1999. Ornithobacterium rhinotracheale: a review. Avian Pathol 28: 217-227. 
30. Van Veen L, Gruys E, Frik K, Van Empel P. 2000a. Increased condemnation of broilers associated with Ornithobacterium rhinotracheale. Vet Rec 147: 422-423.

31. Van Veen L, Van Empel P, Fabri T. 2000b. Ornithobacterium rhinotrachale, $\boldsymbol{a}$ primary pathogen in broilers. Avian Dis 44: 896-900.

32. Yaguchi K, Ohgitani T, Noro T, Kaneshige T, Shimizu Y. 2009.
Vaccination of chickens with liposomal inactivated avian pathogenic Escherichia coli (APEC) vaccine by eye drop or coarse spray administration. Avian Dis 53: 245-249. doi: 10.1637/8475-092908Reg. 1

33. Zaini MZ, Jee TL, Jusoff K. 2008. Phenotypic characteristics, antibiotic susceptibility and pathogenicity of Ornithobacterium rhinotracheale. Wseas T Biol Biomed 5: 133-142. 